\title{
Brevibacterium massiliense sp. nov., isolated from a human ankle discharge
}

\author{
Véronique Roux and Didier Raoult \\ Laboratoire de Bactériologie-Virologie, Hôpital de la Timone, CNRS UMR 6236, IFR48, 264 rue \\ Saint-Pierre, 13385 Marseille, Cedex 05, France
}

Correspondence

Véronique Roux

vroux91@hotmail.com

\begin{abstract}
Gram-positive, non-spore-forming rods, strain $5401308^{\top}$, were isolated from a human ankle discharge. Based on cellular morphology and the results of biochemical testing, this strain was tentatively identified as an undescribed member of the genus Brevibacterium. The major fatty acids were anteiso- $\mathrm{C}_{15: 0}(45.3 \%)$, anteiso- $\mathrm{C}_{17: 0}(19.2 \%)$ and iso- $\mathrm{C}_{15: 0}(18.3 \%)$. Phylogenetic analysis based on $16 \mathrm{~S}$ rRNA gene sequence comparison showed that the bacterium was closely related to the type strains of Brevibacterium mcbrellneri (96.3\% similarity) and Brevibacterium paucivorans ( $95.8 \%)$. On the basis of phenotypic data and phylogenetic inference, it is proposed that this strain represents a novel species, designated Brevibacterium massiliense sp. nov.; the type strain is $5401308^{\top}\left(=\right.$ CSUR P $26^{\top}=$ CIP $109422^{\top}=$ CCUG $\left.53855^{\top}\right)$.
\end{abstract}

Members of the genus Brevibacterium include Grampositive, non-spore-forming, non-branching rods and Brevibacterium linens is the type species of the genus (Skerman et al., 1980). At the time of writing, 17 species with validly published names were included in the genus. Some of them were isolated from environmental samples, but several have been isolated from human samples: Brevibacterium casei (Collins et al., 1983), Brevibacterium epidermidis (Collins et al., 1983), Brevibacterium mcbrellneri (McBride et al., 1993), Brevibacterium otitidis (Pascual et al., 1996), Brevibacterium luteolum (Wauters et al., 2003), Brevibacterium paucivorans (Wauters et al., 2001) and Brevibacterium sanguinis (Wauters et al., 2004). Brevibacterium species have been implicated in corneal ulcers (Ghosheh et al., 2007), bacteraemia (Ulrich et al., 2006), pericardial infection (Cannon et al., 2005), endocarditis (Dass et al., 2002), peritonitis (Antoniou et al., 1997; Wauters et al., 2000) and osteomyelitis in a neonate (Neumeister et al., 1993).

In this report, a novel species belonging to the genus Brevibacterium that is closely related to $B$. mcbrellneri and B. paucivorans and was isolated from a human ankle discharge is described.

A 78-year-old man was admitted to the emergency unit of the Sainte-Marguerite Hospital, Marseille, France. He had been knocked over by a car and presented open dislocation

Abbreviation: MALDI-TOF MS, matrix-assisted laser-desorption/ionization time-of-flight MS.

The GenBank/EMBL/DDBJ accession number for the 16S rRNA gene sequence of Brevibacterium massiliense strain $5401308^{\top}$ is EU868814.

Biolog diagnostic characteristics of Brevibacterium massiliense strain $5401308^{\top}$ and related strains are available as supplementary material with the online version of this paper. of the left ankle and a fibula fracture. The patient was treated with amoxicillin/clavulanic acid for 5 days $\left(3 \mathrm{~g} \mathrm{day}^{-1}\right)$. Three weeks later, a discharge was noted; the liquid was sampled and sent to our laboratory. Grampositive bacilli were isolated and identified (API Coryne; bioMérieux) as a Corynebacterium species. As no phenotypic identification was obtained, genotypic identification based on 16S rRNA gene sequence comparison was performed and showed that the isolate, designated strain $5401308^{\mathrm{T}}$, was a representative of the genus Brevibacterium, but could not be ascribed to any known species.

MICs were determined according to the disc diffusion method as there are, to our knowledge, no international guidelines for the antimicrobial susceptibility testing of actinomycetes. Strain $5401308^{\mathrm{T}}$ was susceptible to rifampicin, doxycycline, vancomycin and amoxicillin, but was resistant to trimethoprim/sulfamethoxazole, erythromycin and gentamicin.

Growth was tested at $37{ }^{\circ} \mathrm{C}$ on Columbia agar with $5 \%$ sheep blood incubated for $24 \mathrm{~h}$ in the presence of air or $5 \% \mathrm{CO}_{2}$ and also in anaerobic and microaerophilic atmospheres that were created using GENbag Anaer and GENbag Microaer (bioMérieux) systems, respectively. The strain was aerobic and also grew in a microaerophilic atmosphere and in the presence of $5 \% \mathrm{CO}_{2}$. Growth in an anaerobic atmosphere was weak after $24 \mathrm{~h}$ incubation. Growth at various temperatures $\left(25,30,37,45\right.$ and $\left.50{ }^{\circ} \mathrm{C}\right)$ was tested. The size and ultrastructure of cells were determined by transmission electron microscopy. Cells were grown on trypticase soy broth for $24 \mathrm{~h}$. Bacterial suspensions were pre-fixed in $5 \%(\mathrm{v} / \mathrm{v})$ glutaraldehyde in phosphate buffer (Gibco) for at least $1 \mathrm{~h}$ at room temperature, washed in the same buffer and stained with $1 \%(\mathrm{w} / \mathrm{v})$ phosphotungstic acid. Samples were examined 
on a Morgagni 268D (Philips) electron microscope at an operating voltage of $60 \mathrm{kV}$.

Catalase activity was determined by using the ID Colour Catalase test kit (bioMérieux). Oxidase activity was assayed by applying cells to moistened discs that were impregnated with dimethyl-p-phenylenediamine (bioMérieux). $\mathrm{NaCl}$ tolerance was studied in trypticase soy broth containing $\mathrm{NaCl}$ at concentrations of $0-15 \%(w / v)$.

The commercially available API ZYM, API Coryne and API Rapid ID 32A strips (bioMérieux) were used to characterize the biochemical properties of the isolate according to the manufacturer's instructions and incubation was performed at $37^{\circ} \mathrm{C}$. Phenotypic characteristics were compared to those of $B$. luteolum CIP $108129^{\mathrm{T}}, B$. mcbrellneri CIP $104342^{\mathrm{T}}$, B. otitidis CIP $105044^{\mathrm{T}}$ and B. paucivorans CIP $107270^{\mathrm{T}}$, which were the most closely related species in terms of their 16S rRNA gene sequence similarities. Characteristic traits are presented in Table 1. Results of other tests on strain $5401308^{\mathrm{T}}$ are given in the species description.

The biochemical characteristics of strain $5401308^{\mathrm{T}}$ were also determined using the Biolog system. Cells were grown on $5 \%$ sheep blood agar (bioMérieux). Bacterial suspensions were made in GP/GN sterile inoculation fluid (Biolog) and added to GP2 Microplates (Biolog) as described by the manufacturer. Incubation was carried out at $36{ }^{\circ} \mathrm{C}$ in an aerobic atmosphere for $21 \mathrm{~h}$ (see Supplementary Table S1, available in IJSEM Online) and read using the fully automated OmniLog system. The tests were repeated at least three times.

Preparation and determination of cellular fatty acids were carried out following the procedures given for the Sherlock Microbial identification System (MIDI). The fatty acid profile was characterized by the predominance of anteiso-

Table 1. Diagnostic traits of the type strains of different Brevibacterium species tested in this study

Strains: 1, B. massiliense $5401308^{\mathrm{T}} ; 2$, B. luteolum CIP $108129^{\mathrm{T}} ; 3$, B. mcbrellneri CIP $104342^{\mathrm{T}} ; 4$, B. otitidis CIP $105044^{\mathrm{T}} ; 5$, B. paucivorans CIP $107270^{\mathrm{T}}$. W, Weakly positive; + , positive; - , negative.

\begin{tabular}{|lccccc|}
\hline Test & $\mathbf{1}$ & $\mathbf{2}$ & $\mathbf{3}$ & $\mathbf{4}$ & $\mathbf{5}$ \\
\hline Oxidase & - & - & - & - & + \\
Gelatin hydrolysis & - & + & $\mathrm{w}$ & + & - \\
Alkaline phosphatase & - & - & - & + & - \\
Esterase lipase $(\mathrm{C} 8)$ & $\mathrm{W}$ & $\mathrm{W}$ & $\mathrm{W}$ & $\mathrm{W}$ & + \\
Pyrazinamidase & $\mathrm{W}$ & + & - & + & - \\
N-Acetyl- $\beta$-glucosaminidase & - & $\mathrm{W}$ & $\mathrm{W}$ & - & - \\
Arginine arylamidase & + & $\mathrm{W}$ & + & + & + \\
Phenylalanine arylamidase & + & + & + & + & - \\
Pyroglutamic acid arylamidase & - & + & - & + & - \\
Tyrosine arylamidase & + & + & - & + & - \\
Histamine arylamidase & $\mathrm{w}$ & $\mathrm{w}$ & $\mathrm{w}$ & - & $\mathrm{W}$ \\
\hline
\end{tabular}

$\mathrm{C}_{15: 0}(45.3 \%)$, anteiso- $\mathrm{C}_{17: 0}(19.2 \%)$, iso- $\mathrm{C}_{15: 0}(18.3 \%)$ and iso- $\mathrm{C}_{16: 0}(8.5 \%)$, which were also found previously in Brevibacterium species that clustered with strain $5401308^{\mathrm{T}}$.

Matrix-assisted laser-desorption/ionization time-of-flight (MALDI-TOF) MS protein analysis was carried out. Smear bacterial material was deposited on each spot of a polishedsteel target plate. After air-drying, $1.5 \mu \mathrm{l}$ matrix solution (saturated solution of $\alpha$-cyanohydroxycinnaminic acid in $50 \%$ aqueous acetonitrile containing $2.5 \%$ trifluoroacetic acid) per spot was applied. MALDI-TOF MS was conducted using an Autoflex II MS (Bruker Daltonics). All spectra were recorded in linear, positive ion mode. The acceleration voltage was $20 \mathrm{kV}$. Spectra were collected as a sum of 675 shots across a spot. The manipulation was repeated 15 times for strain $5401308^{\mathrm{T}}$ and the type strains of B. luteolum, B. mcbrellneri, B. otitidis, B. paucivorans and eight other representatives of the genus Brevibacterium. Preprocessing and identification steps were performed using the manufacturer's parameters. Consensus spectra were obtained. Scores obtained for the spectra of strain $5401308^{\mathrm{T}}$ were significant $(>2.2)$ only with those of strain $5401308^{\mathrm{T}}$ and were $<2.2$ with spectra of all other strains tested, thus indicating that strain $5401308^{\mathrm{T}}$ belongs to a novel species. A taxonomic tree was obtained by using the principal component analysis clustering method (Fig. 1). Strain $5401308^{\mathrm{T}}$ clustered with the type strains of $B$. luteolum, B. mcbrellneri, B. otitidis and B. paucivorans.

Bacterial DNA was extracted using the MagNA Pure LC DNA isolation kit III (Roche) with the MagNA Pure LC instrument as described by the manufacturer. PCR amplification of the 16S rRNA gene was performed using the universal primer pair $\mathrm{fD} 1$ and $\mathrm{rp} 2$ (Weisburg et al., 1991). PCR products were purified using MultiScreen PCR (Millipore) and sequencing reactions were carried out using a DNA sequencing kit (BigDye Terminator v1.1 Cycle Sequencing kit; PE Applied Biosystems) according to the manufacturer's instructions. Sequencing products were purified and electrophoresis was performed with the 3130 Genetic Analyzer (Applied Biosystems). The sequences obtained were compared with sequences deposited in GenBank by using the program BLAST through the NCBI server. Gene sequences were aligned using the multisequence alignment program CLUSTAL_X (1.8). Phylogenetic relationships with strains of closely related species were determined by using MEGA version 4.0 (Tamura et al., 2007). Distance matrices were determined following the assumptions described by Kimura (1980) and were used to elaborate a dendrogram using the neighbour-joining method (Saitou \& Nei, 1987). The maximum-parsimony algorithm was also used to infer phylogenetic analysis. Bootstrap analysis (bootstrap values were obtained for a consensus tree based on 100 randomly generated trees) was performed to investigate the stability of the trees obtained. Phylogenetic analysis demonstrated that our isolate is a member of the genus Brevibacterium, as it clustered with the type strains of $B$. mcbrellneri and B. paucivorans with the neighbour-joining method (Fig. 2). The same result 


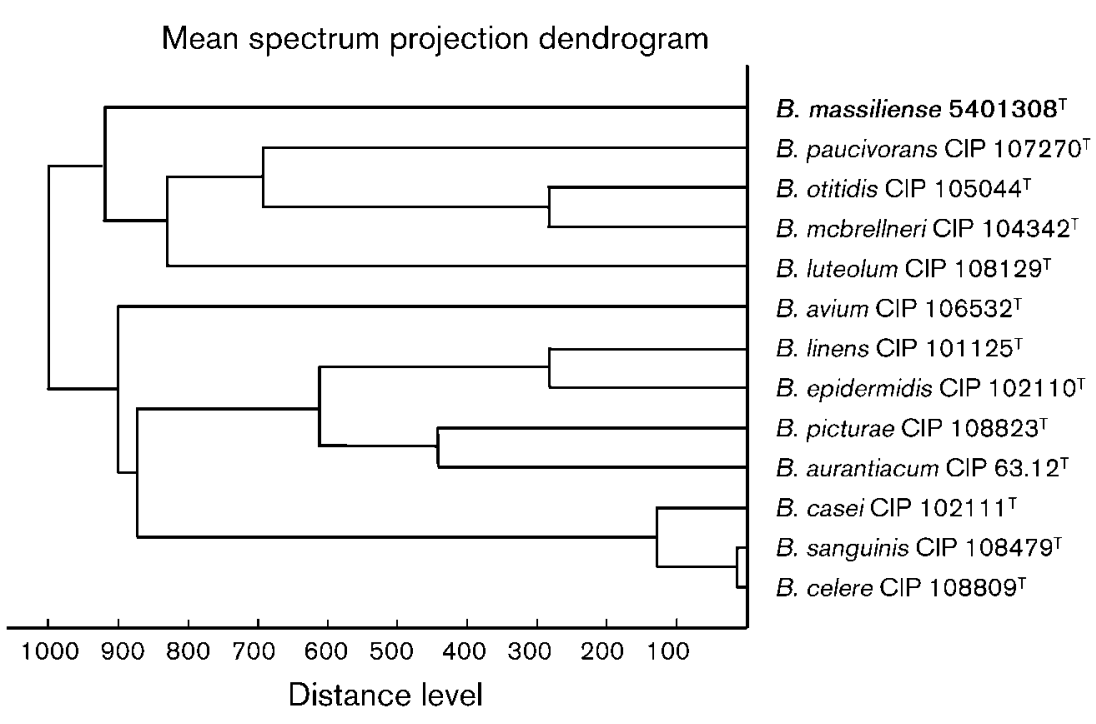

Fig. 1. Dendrogram generated by using BIOTYPER software (version 2; Bruker Daltonics) showing the similarity of MALDITOF mass spectra of strain $5401308^{\top}$ and representatives of the genus Brevibacterium. was obtained with the maximum-parsimony algorithm. 16S rRNA gene sequence similarities (\%) were determined by using CLUSTAL_X and MEGA version 4.0. Similarity values between strain $5401308^{\mathrm{T}}$ and the type strains of $B$. luteolum, B. otitidis, B. mcbrellneri and B. paucivorans were 96.6, 96.6, 96.3 and $95.8 \%$, respectively. These values are $<97 \%$, which is the value retained by the ad hoc committee to determine the species level, thus confirming that strain $5401308^{\mathrm{T}}$ belongs to a novel species (Stackebrandt et al., 2002). Based on results described above, the name Brevibacterium massiliense sp. nov. is proposed for this novel species, with strain $5401308^{\mathrm{T}}$ as the type strain.

\section{Description of Brevibacterium massiliense sp. nov.}

Brevibacterium massiliense (mas.si.li.en'se. L. neut. adj. massiliense of Massilia, the old Roman name for Marseille, where the type strain was isolated).

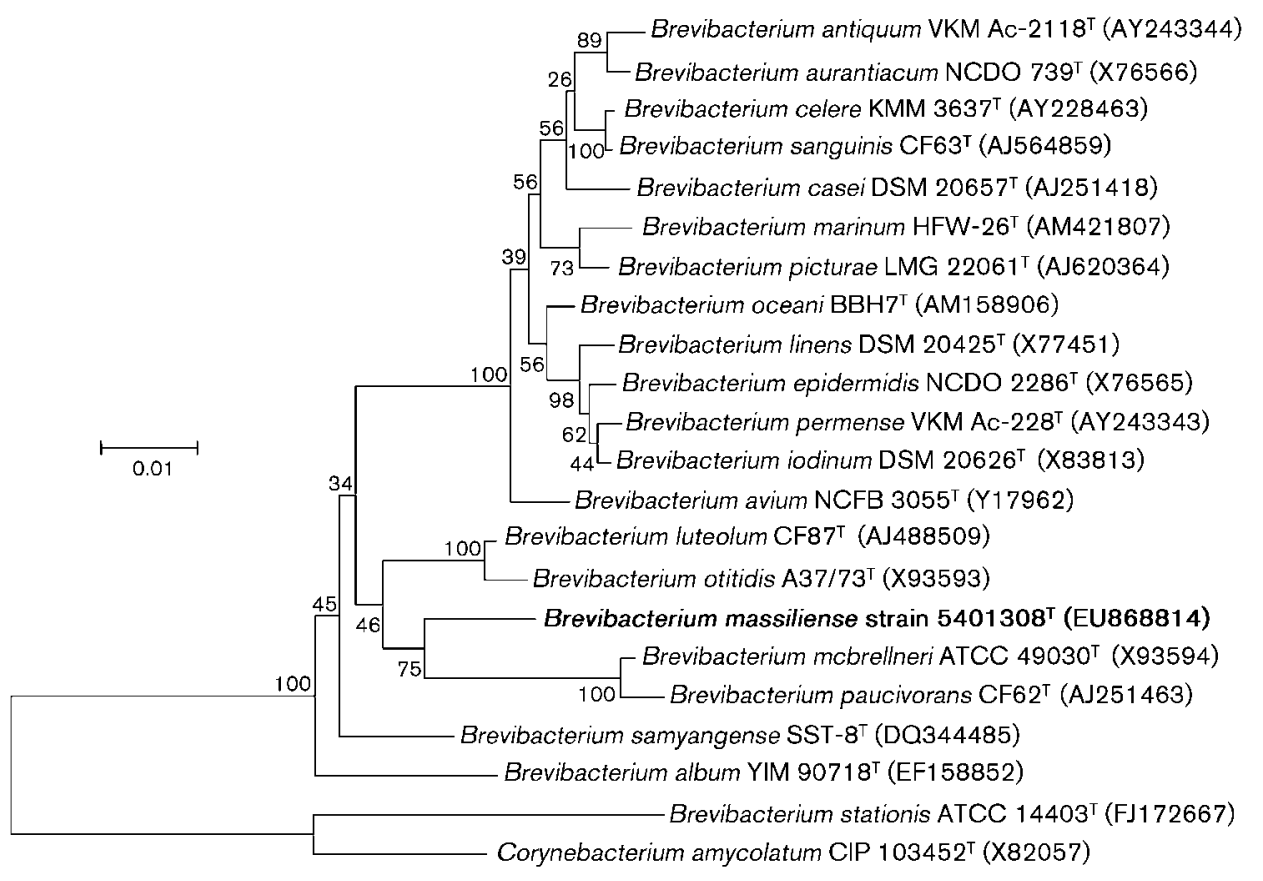

Fig. 2. Phylogenetic tree of representatives of the genus Brevibacterium inferred from $16 \mathrm{~S}$ rRNA gene sequence comparison (1386 nt fragment). Numbers at nodes are proportions of 100 resamplings that support the topology shown. Corynebacterium amycolatum was used as the outgroup. Bar, $0.01 \mathrm{nt}$ changes per nucleotide position. 
Cells are aerobic, Gram-positive, non-spore-forming and non-motile. They are short, irregular, straight rods, 0.4 $1.4 \mu \mathrm{m}$ in length and $0.3-0.5 \mu \mathrm{m}$ in diameter, as determined by electron microscopy. Catalase-positive and oxidase-negative. Grows between 25 and $45{ }^{\circ} \mathrm{C}$, with optimal growth at $30-37{ }^{\circ} \mathrm{C}$. After $24 \mathrm{~h}$ growth in $5 \%$ $\mathrm{CO}_{2}$ on sheep blood agar, surface colonies are beige, shiny, smooth, circular and $0.2 \mathrm{~mm}$ in diameter. Tolerates $\mathrm{NaCl}$, with good growth in $1-10 \% \mathrm{NaCl}$; no growth is observed in $15 \% \mathrm{NaCl}$. Using the API ZYM system, esterase (C4) and leucine arylamidase activities are detected. Esterase lipase (C8) activity is weakly positive. Alkaline phosphatase, lipase (C14), valine arylamidase, cystine arylamidase, trypsin, $\alpha$-chymotrypsin, acid phosphatase, naphthol-ASBI-phosphohydrolase, $\alpha$-galactosidase, $\beta$-galactosidase, $\beta$ glucuronidase, $\alpha$-glucosidase, $\beta$-glucosidase, $N$-acetyl $\beta$ glucosaminidase, $\alpha$-mannosidase and $\alpha$-fucosidase activities are not detected. Using API Coryne, pyrazinamidase activity is weakly positive. Reduction of nitrates and hydrolysis of gelatin are negative. Pyrrolidonyl arylamidase, alkaline phosphatase, $\beta$-glucuronidase, $\beta$-galactosidase, $\alpha$ glucosidase, $\quad N$-acetyl- $\beta$-glucosaminidase, $\beta$-glucosidase and urease activities are negative. Negative for fermentation of all carbohydrates tested. Using API 32A, arginine arylamidase, proline arylamidase, leucyl glycine arylamidase, phenylalanine arylamidase, leucine arylamidase, tyrosine arylamidase, alanine arylamidase, glycine arylamidase and serine arylamidase activities are detected. Histidine arylamidase activity is weakly positive. Urease, arginine dihydrolase, $\alpha$-galactosidase, $\beta$-galactosidase, 6 phospho- $\beta$-galactosidase, $\alpha$-glucosidase, $\beta$-glucosidase, $\alpha$ arabinosidase, $\beta$-glucuronidase, $N$-acetyl- $\beta$-glucosaminidase, glutamic acid decarboxylase, $\alpha$-fucosidase, alkaline phosphatase, pyroglutamic acid arylamidase and glutamyl glutamic acid arylamidase activities are not detected. Mannose fermentation, raffinose fermentation, reduction of nitrates and indole production are negative.

Positive biochemical traits recovered when using the Biolog system are as follows: Tween 40 , Tween 80 , acetic acid, $\alpha$ hydroxybutyric acid, $\beta$-hydroxybutyric acid, $\gamma$-hydroxybutyric acid, $\alpha$-ketovaleric acid, L-lactic acid, pyruvic acid methyl ester, succinic acid monomethyl ester, propionic acid, pyruvic acid, $N$-acetyl-L-glutamic acid, L-alaninamide, D-alanine, L-alanine, L-alanyl glycine, L-asparagine, L-glutamic acid, glycyl L-glutamic acid, L-serine and 2,3butanediol. The following traits are weakly positive: lactamide and TMP. The following traits are negative: $\alpha$ cyclodextrin, $\beta$-cyclodextrin, dextrin, glycogen, mannan, $N$-acetyl-D-glucosamine, amygdalin, L-arabinose, D-arabitol, arbutin, cellobiose, D-fructose, L-fucose, D-galactose, Dgalacturonic acid, gentiobiose, D-gluconic acid, $\beta$-Dglucose, myo-inositol, $\alpha$-D-lactose, lactulose, maltose, maltotriose, D-mannitol, D-mannose, melezitose, melibiose, methyl $\alpha$-D-galactoside, methyl $\beta$-D-galactoside, 3 -methyl glucose, methyl $\alpha$-D-glucoside, methyl $\beta$-D-glucoside, methyl $\alpha$-D-mannoside, palatinose, D-psicose, raffinose, Lrhamnose, salicin, sedoheptulosan, D-sorbitol, stachyose, sucrose, D-tagatose, trehalose, turanose, xylitol, D-xylose, $p$-hydroxyphenylacetic acid, $\alpha$-ketoglutaric acid, D-lactic acid methyl ester, D-malic acid, L-malic acid, succinamic acid, succinic acid, L-pyroglutamic acid, putrescine, glycerol, adenosine, $2^{\prime}$-deoxyadenosine, inosine, thymidine, uridine, AMP, UMP, D-fructose 6-phosphate, $\alpha$-D-glucose 1-phosphate, D-glucose 6-phosphate and DL- $\alpha$-glycerol phosphate. The following traits are not reproducible: $N$ acetyl- $\beta$-D-mannosamine and D-ribose.

The fatty acid profile is characterized by the predominance of anteiso- $\mathrm{C}_{15: 0}$, anteiso- $\mathrm{C}_{17: 0}$, iso- $\mathrm{C}_{15: 0}$ and iso- $\mathrm{C}_{16: 0}$.

The type strain, $5401308^{\mathrm{T}}\left(=\mathrm{CSUR} \mathrm{P} 26^{\mathrm{T}}=\mathrm{CIP} 109422^{\mathrm{T}}=\right.$ CCUG $53855^{\mathrm{T}}$ ), was isolated from a human ankle discharge sample.

\section{Acknowledgements}

We are grateful to Audrey Borg for her technical assistance in electron microscopy and to Philippe Decloquement and Carine Couderc for their assistance in mass spectrometry analysis.

\section{References}

Antoniou, S., Dimitriadis, A., Polydorou, F. \& Malaka, E. (1997). Brevibacterium iodinum peritonitis associated with acute urticaria in a CAPD patient. Perit Dial Int 17, 614-615.

Cannon, J. P., Spandoni, S. L., Pesh-Iman, S. \& Johnson, S. (2005). Pericardial infection caused by Brevibacterium casei. Clin Microbiol Infect 11, 164-165.

Collins, M. D., Farrow, J. A. E., Goodfellow, M. \& Minnikin, D. E. (1983). Brevibacterium casei sp. nov. and Brevibacterium epidermidis sp. nov. Syst Appl Microbiol 4, 388-395.

Dass, K. N., Smith, M. A., Gill, V. J., Goldstein, S. A. \& Lucey, D. R. (2002). Brevibacterium endocarditis: a first report. Clin Infect Dis 35, e20-e21.

Ghosheh, F. R., Ehlers, J. P., Ayres, B. D., Hammersmith, K. M., Rapuano, C. J. \& Cohen, E. J. (2007). Corneal ulcers associated with aerosolized crack cocaine use. Cornea 26, 966-969.

Kimura, M. (1980). A simple method for estimating evolutionary rates of base substitutions through comparative studies of nucleotide sequences. J Mol Evol 16, 111-120.

McBride, M. E., Ellner, K. M., Black, H. S., Clarridge, J. E. \& Wolf, J. E. (1993). A new Brevibacterium sp. isolated from infected genital hair of patients with white piedra. J Med Microbiol 39, 255-261.

Neumeister, B., Mandel, T., Gruner, E. \& Pfyffer, G. E. (1993). Brevibacterium species as a cause of osteomyelitis in a neonate. Infection 21, 177-178.

Pascual, C., Collins, M. D., Funke, G. \& Pitcher, D. G. (1996). Phenotypic and genotypic characterization of two Brevibacterium strains from the human ear: description of Brevibacterium otitidis sp. nov. Med Microbiol Lett 5, 113-123.

Saitou, N. \& Nei, M. (1987). The neighbor-joining method: a new method for reconstructing phylogenetic trees. Mol Biol Evol 4, 406425.

Skerman, V. B. D., McGowan, V. \& Sneath, P. H. A. (editors) (1980). Approved lists of bacterial names. Int J Syst Bacteriol 30, $225-420$. 
Stackebrandt, E., Frederiksen, W., Garrity, G. M., Grimont, P. A. D., Kämpfer, P., Maiden, M. C. J., Nesme, X., Rosselló-Mora, R., Swings, J. \& other authors (2002). Report of the ad hoc committee for the re-evaluation of the species definition in bacteriology. Int $J$ Syst Evol Microbiol 52, 1043-1047.

Tamura, K., Dudley, J., Nei, M. \& Kumar, S. (2007). MEGA4: Molecular Evolutionary Genetics Analysis (MEGA) software version 4.0. Mol Biol Evol 24, 1596-1599.

Ulrich, S., Zbinden, R., Pagano, M., Fischler, M. \& Speich, R. (2006). Central venous catheter infection with Brevibacterium sp. in an immunocompetent woman: case report and review of the literature. Infection 34, 103-106.

Wauters, G., Van Bosterhaut, B., Avesani, V., Cuvelier, R., Charlier, J., Janssens, M. \& Delmée, M. (2000). Peritonitis due to Brevibacterium otitidis in a patient undergoing continuous ambulatory peritoneal dialysis. J Clin Microbiol 38, 4292-4293.
Wauters, G., Charlier, J., Janssens, M. \& Delmée, M. (2001). Brevibacterium paucivorans sp. nov., from human clinical specimens. Int J Syst Evol Microbiol 51, 1703-1707.

Wauters, G., Avesani, V., Laffineur, K., Charlier, J., Janssens, M., Van Bosterhaut, B. \& Delmée, M. (2003). Brevibacterium lutescens sp. nov., from human and environmental samples. Int $J$ Syst Evol Microbiol 53, 1321-1325.

Wauters, G., Haase, G., Avesani, V., Charlier, J., Janssens, M., Van Broeck, J. \& Delmée, M. (2004). Identification of a novel Brevibacterium species isolated from humans and description of Brevibacterium sanguinis sp. nov. J Clin Microbiol 42, 28292832.

Weisburg, W. G., Barns, S. M., Pelletier, D. A. \& Lane, D. J. (1991). 16 S ribosomal DNA amplification for phylogenetic study. J Bacteriol 173, 697-703. 